\title{
Inclusion Characterization of Lanthana-Doped Molybdenum Wire
}

\author{
L.E. Iorio, B.P. Bewlay and M. Larsen
}

General Electric Global Research Center, P.O. Box 8, Schenectady, New York 12301.

Molybdenum wire and foil are used in the incandescent lamp industry for coiling mandrels, filament support wires, foil seals, and reflectors for halogen lamps. The Mo is frequently doped in order to improve the high-temperature strength and increase the recrystallization temperature.

Most commonly, Mo is doped with potassium and produced in a similar manner to aluminumpotassium-silicon (AKS) doped tungsten, however lower processing temperatures are typically used in the production of Mo. The effect of doping Mo with $\mathrm{K}, \mathrm{Al}$ and $\mathrm{Si}$ is to increase the recrystallization temperature of the Mo and to produce a microstructure of coarse, interlocking grains after recrystallization with rows of fine potassium bubbles pinning the grain boundaries.

An alternative dopant is lanthana [1-3]. Lanthana-doped Mo has been reported to have recrystallization temperatures above those obtained through AKS-doping [1,2] as well as a grain structure similar to the coarse, interlocked grains observed in AKS-doped Mo, although little microstructural analysis has been reported on this material. Lanthana particles are stable within Mo since lanthanum has very limited solubility in Mo [4].

The microstructure of $0.4 \mathrm{wt} \%$ lanthana-doped $0.64 \mathrm{~mm}$ Mo wire was analyzed in the as-drawn condition, after heat treatment at $1800^{\circ} \mathrm{C}$ for 30 minutes, and after heat treatment at $2350^{\circ} \mathrm{C}$ for 30 minutes. The microstructure of the heat treated material was compared to that of AKS-doped Mo wire after similar heat treatments. TEM foils were made from the wire samples by inserting the wire into a platinum tube, pressing the tube flat and then mechanically grinding a longitudinal section of the tube until the wire was visible on both sides. The samples were electropolished in a solution of $20 \%$ perchloric acid in methanol at $-30^{\circ} \mathrm{C}$. Transmission electron microscopy was performed using a JEOL 2010 EM operated at $200 \mathrm{kV}$ with an Oxford ISIS EDS system.

In the as-drawn condition, the lanthana-doped Mo had a fibrous grain structure, as shown in Figure 1. Fiber widths of less than $0.6 \mu \mathrm{m}$ were noted. A low number density of large particles $(0.5-1.0 \mu \mathrm{m})$ rich in La was observed, in addition to a higher number density of fine particles $(0.05-0.1 \mu \mathrm{m})$ which also appeared to contain La, as indicated by the EDS spectrum shown in Figure 1. The fine particles were aligned in rows within the grains and are ellipsoidal in shape. After heat treatment at $1800^{\circ} \mathrm{C}$, the fiber boundaries were not frequently observed. In the $2350^{\circ} \mathrm{C} / 30 \mathrm{~min}$ condition the fibrous structure of the grains was completely absent, however the dislocation density remained relatively high. The fine lanthana particles were still present but they were found to be more spherical in shape and less well-aligned in rows. The dislocation density of the lanthana-doped Mo after heat treatment at $2350^{\circ} \mathrm{C}$ is found to be higher than that observed in an AKS-doped Mo wire after the same heat treatment, as can be seen by comparison of Figures 2 and 3. The higher dislocation density in the lanthana-doped Mo wire is an indication that this material has a higher recrystallization temperature than the AKS-doped Mo material. 


\section{References}

[1] G. Leichtfried et al., Int. J. Refractory Met. \& Hard Met., 16 (1998) 13-22.

[2] US Patent 4950327.

[3] R. Bianco and R.W. Buckmann, Jr, Molybdenum and Molybdenum Alloys, Proceedings from $127^{\text {th }}$ Annual TMS Meeting, (1998) 125-142.

[4] L. Brewer et al., Molybenum: Physico-chemical properties of its compounds and alloys, International Atomic Energy Agency, Vienna, 1980.

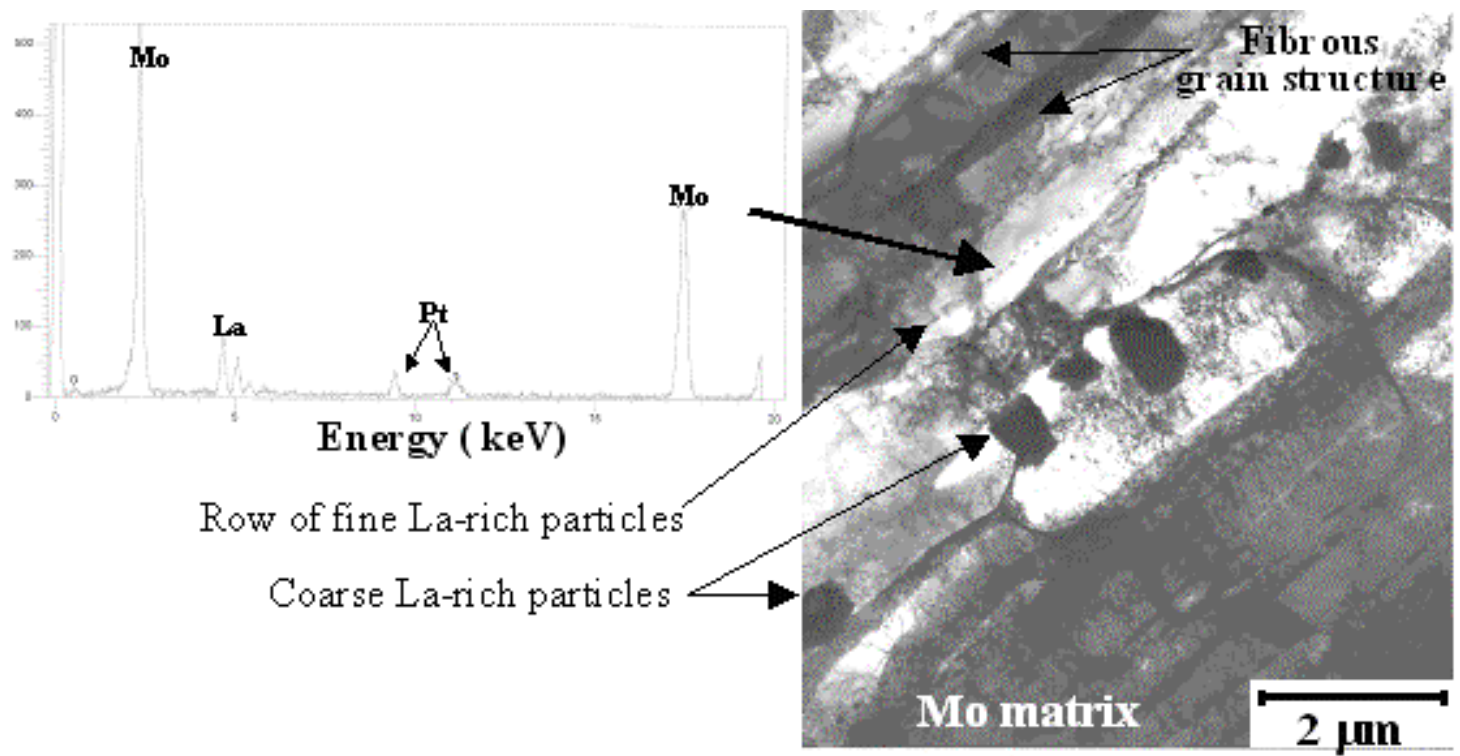

Figure 1: Micrograph of lanthana particles in as-drawn lanthana-doped Mo wire and EDS spectrum of a fine lanthana particle.

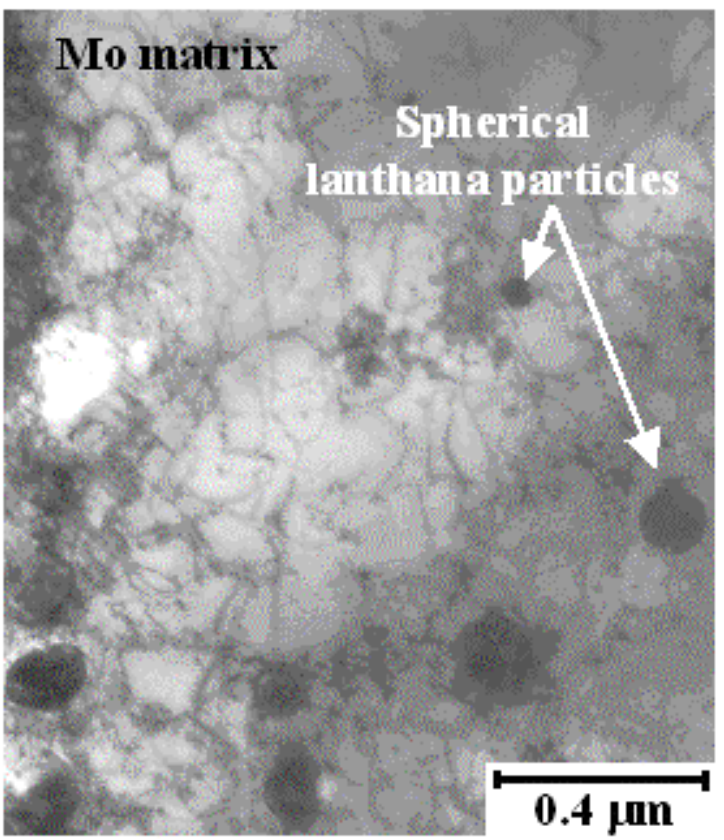

Figure 2: Micrograph of dopant particles in lanthana-Mo wire after $2350^{\circ} \mathrm{C}$.

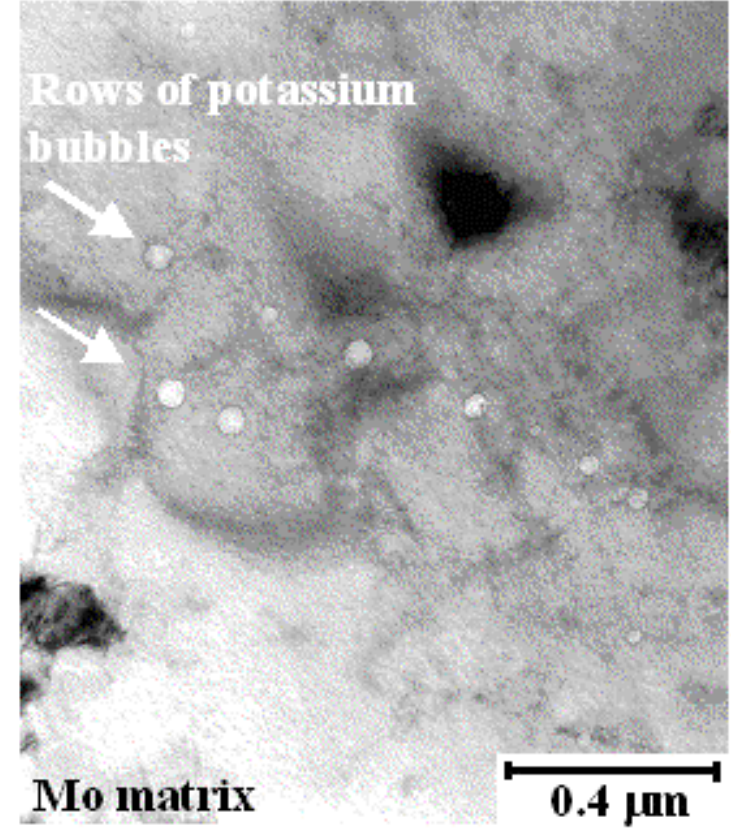

Figure 3: Micrograph of potassium bubbles in AKS doped-Mo wire after $2350^{\circ} \mathrm{C}$. 